\title{
Correction to: New Disulfide-Linked Dinitroxides and the Kinetics of Their Reaction with Glutathione
}

\author{
Mitasha S. Palha ${ }^{1,2}$ - Eric A. Legenzov ${ }^{1,4} \cdot$ Nathaniel D. A. Dirda ${ }^{1}$ \\ Gerald M. Rosen ${ }^{3}$. Joseph P. Y. Kao ${ }^{1,4}$
}

Published online: 20 July 2021

๑) Springer-Verlag GmbH Austria, part of Springer Nature 2021

\section{Correction to: Applied Magnetic Resonance https://doi.org/10.1007/s00723-021-01332-3}

In the online published article, Fig. 1 caption has been published incorrectly and the correct caption is given below.

Schematic representation of disulfide-linked dinitroxide, their cleavage by glutathione (GSH), and EPR spectra of the intact dimeric and cleaved monomeric forms

The entire set of footnotes $(\mathrm{a}-\mathrm{d})$ for Table 1 were reproduced a second time on page 9 of the article (the 3rd page from the end). The footnote text was inserted at the end of the second full paragraph "For each ... Khramtsov and colleagues [11, 12]." This extra text has been deleted.

The original article can be found online at https://doi.org/10.1007/s00723-021-01332-3.

Joseph P. Y. Kao

jkao@som.umaryland.edu

1 Center for Biomedical Engineering and Technology (BioMET), University of Maryland School of Medicine, Baltimore, USA

2 Department of Biochemistry, University of Maryland School of Medicine, Baltimore, USA

3 Department of Pharmaceutical Sciences, University of Maryland School of Pharmacy, Baltimore, USA

4 Department of Physiology, University of Maryland School of Medicine, Baltimore, USA 
Publisher's Note Springer Nature remains neutral with regard to jurisdictional claims in published maps and institutional affiliations. 